\title{
OPEN BMP signaling suppresses Gemc1 expression and ependymal differentiation of mouse telencephalic progenitors
}

\author{
Hanae Omiya ${ }^{1}$, Shima Yamaguchi ${ }^{1}$, Tomoyuki Watanabe ${ }^{1}$, Takaaki Kuniya ${ }^{1}$, Yujin Harada ${ }^{1}$, \\ Daichi Kawaguchi $^{1 \rrbracket}$ \& Yukiko Gotoh ${ }^{1,2 \rrbracket}$
}

The lateral ventricles of the adult mammalian brain are lined by a single layer of multiciliated ependymal cells, which generate a flow of cerebrospinal fluid through directional beating of their cilia as well as regulate neurogenesis through interaction with adult neural stem cells. Ependymal cells are derived from a subset of embryonic neural stem-progenitor cells (NPCs, also known as radial glial cells) that becomes postmitotic during the late embryonic stage of development. Members of the Geminin family of transcriptional regulators including GemC1 and Mcidas play key roles in the differentiation of ependymal cells, but it remains largely unclear what extracellular signals regulate these factors and ependymal differentiation during embryonic and early-postnatal development. We now show that the levels of Smad1/5/8 phosphorylation and Id1/4 protein expression-both of which are downstream events of bone morphogenetic protein (BMP) signaling-decline in cells of the ventricularsubventricular zone in the mouse lateral ganglionic eminence in association with ependymal differentiation. Exposure of postnatal NPC cultures to BMP ligands or to a BMP receptor inhibitor suppressed and promoted the emergence of multiciliated ependymal cells, respectively. Moreover, treatment of embryonic NPC cultures with BMP ligands reduced the expression level of the ependymal marker Foxj1 and suppressed the emergence of ependymal-like cells. Finally, BMP ligands reduced the expression levels of Gemc1 and Mcidas in postnatal NPC cultures, whereas the BMP receptor inhibitor increased them. Our results thus implicate BMP signaling in suppression of ependymal differentiation from NPCs through regulation of Gemc1 and Mcidas expression during embryonic and early-postnatal stages of mouse telencephalic development.

Ependymal cells are multiciliated epithelial cells that constitute the wall of the lateral ventricles in the adult mammalian brain. The coordinated beating of the cilia of these cells generates a flow of cerebrospinal fluid (CSF) that carries essential nutrients to and removes waste material from central nervous system (CNS) tissue ${ }^{1-5}$. Impairment of ependymal cell differentiation during development thus leads to brain malformation and disorders such as hydrocephalus s, $6-13^{2}$.

The subventricular zone (SVZ) of the lateral ventricles in adult mice is a neurogenic niche where neural stem cells (NSCs) produce neurons throughout life ${ }^{14-16}$. These NSCs and surrounding ependymal cells form a pinwheel architecture at the ventricular surface ${ }^{17}$, and the ependymal cells regulate the number and activity of the NSCs via secreted and membrane proteins and thereby control the rate of neurogenesis ${ }^{18-21}$. The flow of CSF promotes the migration of SVZ-derived newborn neurons to the olfactory bulb in an epithelial sodium channel dependent manner ${ }^{22,23}$, with ependymal cells therefore playing essential roles in adult neurogenesis.

Ependymal cells of the lateral ventricles are derived from a subpopulation of neural stem-progenitor cells (NPCs, also known as radial glial cells) that becomes postmitotic at the late embryonic stage of development [around embryonic day (E) 14 in mice] ${ }^{24}$. A specific subpopulation of NPCs that constitutes the embryonic origin of adult NSCs in the lateral SVZ also becomes postmitotic at E13 to E15 in mice ${ }^{25,26}$. Recent studies have shown that some ependymal cells and adult NSCs share a common origin at the late embryonic stage ${ }^{27,28}$. The Geminin family of cell cycle and transcriptional regulators-including Geminin, GemC1 (also known as Gmnc

${ }^{1}$ Graduate School of Pharmaceutical Sciences, The University of Tokyo, 7-3-1 Hongo, Bunkyo-ku, Tokyo 113-0033, Japan. ${ }^{2}$ International Research Center for Neurointelligence (WPI-IRCN), The University of Tokyo, 7-3-1 Hongo, Bunkyo-ku, Tokyo 113-0033, Japan. ${ }^{\circledR}$ email: dkawaguchi@mol.f.u-tokyo.ac.jp; ygotoh@mol.f.u-tokyo.ac.jp 
a

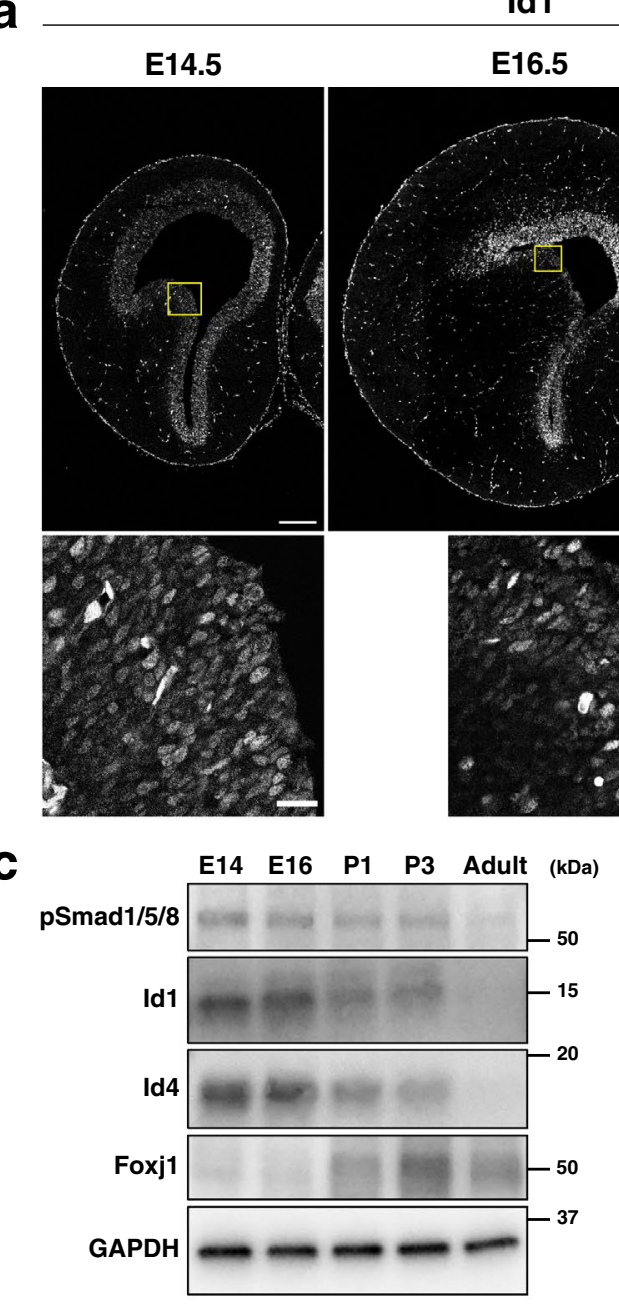

d
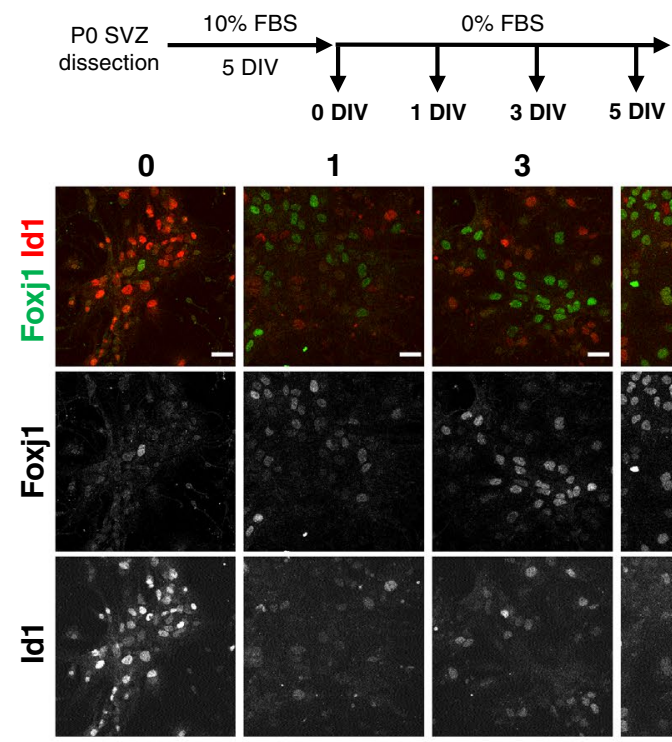

1

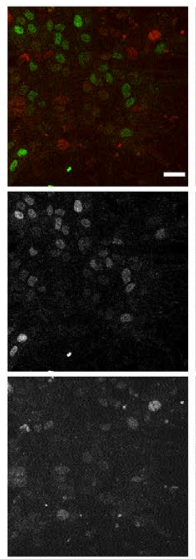

3

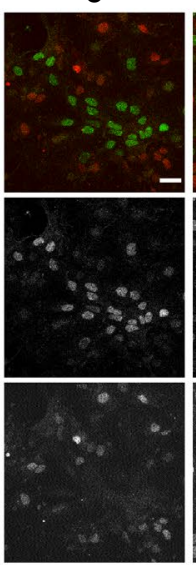

e

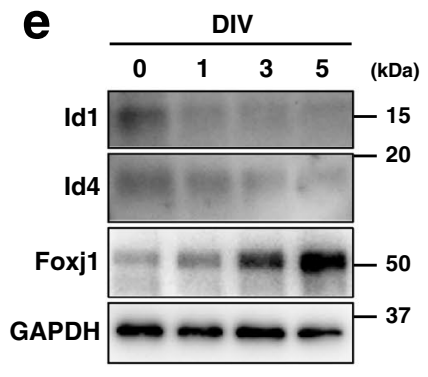

b

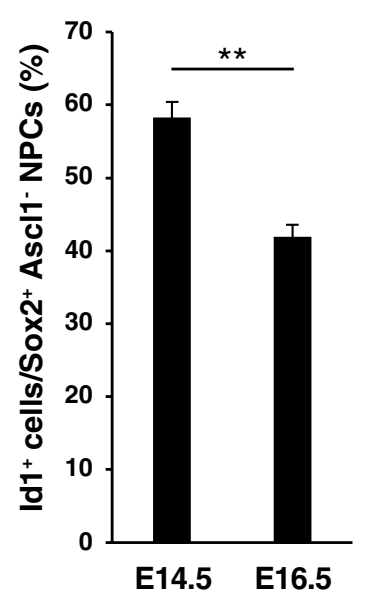

b

E14.5 E16.5
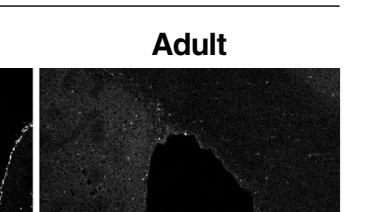

$\square$

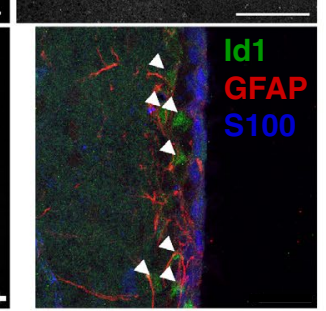


4Figure 1. BMP signaling declines during ependymal cell differentiation. (a) Immunohistofluorescence analysis of Id1 in the LGE of the embryonic mouse brain at E14.5 or E16.5 as well as of Id1, glial fibrillary acidic protein (GFAP), and S100 in the SVZ of the lateral ventricles in the adult mouse brain (P56-P63). The boxed regions of the upper panels are shown at higher magnification in the corresponding lower panels. Arrowheads indicate Id $1^{+}$cells. Scale bars, $200 \mu \mathrm{m}$ (upper panels) or $20 \mu \mathrm{m}$ (lower panels). Data are representative of three independent experiments. (b) Quantification by immunohistofluorescence analysis of Id $1^{+}$cells among Sox $2^{+}$Ascl1 $^{-}$NPCs in the LGE at E14.5 and E16.5. Data are means \pm SEM $(n=3$ embryos for each stage). Three sections were counted per sample. Total of $500-800$ cells were counted per section. ${ }^{* *} p<0.01$ (two-tailed Student's unpaired $t$ test). (c) Immunoblot analysis of the VZ-SVZ of the embryonic GE and corresponding postnatal basal ganglia at the indicated embryonic, postnatal, and young adult (P30) stages with antibodies to phosphorylated (p) Smad1/5/8, to Id1, to Id4, and to glyceraldehyde-3-phosphate dehydrogenase (GAPDH, loading control). Data are representative of three independent experiments, with each experiment analyzed several times. (d) Dissociated cells of the lateral ventricular wall of P0 mice were cultured first for 5 days in vitro (DIV) in the presence of $10 \%$ FBS (proliferation medium) and then for up to 5 DIV in the absence of serum (differentiation medium). The cells were subjected to immunocytofluorescence staining with antibodies to Foxj1 and to Id 1 at the indicated times. Scale bars, $20 \mu \mathrm{m}$. Data are representative of three independent experiments. (e) Immunoblot analysis of cultures as in (d) with antibodies to Id1, to Id4, and to GAPDH. Data are representative of three independent experiments. (f) Id 1 immunofluorescence intensity in Foxj $1^{+}$cells $(n=395)$ and Foxj $1^{-}$cells $(n=484)$ in cultures as in $(\mathbf{d})$ analyzed at 5 DIV. Each dot represents one cell, and the red bar indicates the median. Data are from three independent experiments. ${ }^{\star * *} p<0.001$ (two-tailed Student's unpaired $t$ test).

or Lynkeas), and Mcidas (Mci or Idas) - as well as the Forkhead family protein Foxj1 play pivotal roles in fate specification and differentiation of ependymal cells during development ${ }^{28-34}$. Both GemC1 and Mcidas have been shown to promote multiciliated cell differentiation in the brain and other organs (such as the airways and reproductive organs $)^{35-39}$. Various gain- and loss-of function studies have revealed that GemC1 regulates early specification of multiciliated cells and acts upstream of Mcidas and Foxj1, whereas Mcidas promotes basal body amplification and maturation of multiciliated cells together with the transcription factors TAp73, c-Myb, $\mathrm{E} 2 \mathrm{~F} 4$, and E2F5 $5^{30,31,39-45}$. In the context of embryonic NPCs in the SVZ, whereas overexpression of Geminin increases the number of clones that contain adult NSCs, that of GemC1 increases the number of those containing muticiliated ependymal cells, supporting the notion that GemC1 plays a key role in the early fate specification of ependymal cell ${ }^{28}$. Whereas Notch signaling, epidermal growth factor receptor (EGFR) signaling, and the extracellular matrix (ECM) protein dystroglycan have been shown to regulate the expression of Mcidas and Foxj1 during ependymal maturation ${ }^{31,46-48}$, little is known of the extracellular signals that may regulate the expression of GemC1 and thereby contribute to the specification and differentiation of ependymal cells during embryonic and early-postnatal telencephalic development.

Bone morphogenetic proteins (BMPs) belong to the transforming growth factor- $\beta$ (TGF- $\beta$ ) superfamily of cytokines and are recognized by type I receptors (BMPR1A/ALK3, BMPR1B/ALK6, and ActR-I/ALK2) and type II receptors (BMPR-II/BMPR2, ActR-II, and ActR-IIB) ${ }^{49}$. BMP2 and BMP4 preferentially bind to ALK3 and ALK6, whereas BMP6 and BMP7 bind to ALK2 and, to a lesser extent, to ALK6 ${ }^{49}$. Activation of these receptor serine-threonine kinases results in the phosphorylation and consequent activation of R-Smads (Smad1, Smad5, and Smad8), which, together with Co-Smad (Smad4), induce transcription of downstream target genes including those for the Id family of transcription factors ${ }^{49}$. BMPs perform a variety of functions during development of the vertebrate CNS, ranging from the induction of neuroectoderm and its dorsoventral patterning to regulation of the proliferation, survival, and neuronal and glial differentiation of NPCs ${ }^{50}$. In the adult mouse brain, BMP-Id signaling also contributes to the maintenance of quiescent NSCs ${ }^{51-54}$.

We here show that the levels of phosphorylated R-Smads and of Id proteins decline during the course of mouse telencephalic development in a manner that appears to coincide both temporally and spatially with the differentiation of ependymal cells. We found that forced activation or inhibition of BMP signaling suppressed or promoted multiciliated ependymal cell differentiation, respectively, in primary NPC cultures isolated from the embryonic and postnatal mouse telencephalon. We also found that BMP signaling suppressed the expression of Gemc1, Mcidas, and Foxj1 genes as well as the differentiation of ependymal-like cells even in embryonic NPC cultures. Our results thus implicate BMP signaling in suppression of ependymal differentiation at the embryonic and early-postnatal stages of development of the mouse telencephalon.

\section{Results}

BMP signaling declines during SVZ development coincident with the initial phase of ependymal differentiation. Id1 and Id4 proteins have been shown to maintain the quiescence of NSCs in the adult SVZ ${ }^{52-54}$. Only a minor fraction of cells in the adult mouse SVZ (presumably, adult NSCs) show a high level of Id1 expression, whereas $S 100^{+}$ependymal cells show a low level of Id1 expression ${ }^{52}$ (Fig. 1a). We first asked whether the levels of Id 1 and Id4 proteins are regulated during SVZ development. We found that Id1 immunofluorescence intensity varied among NPCs in the ventricular zone (VZ) of the lateral ganglionic eminence (LGE) even at E14.5 (Fig. 1a). Moreover, the overall level of Id1 immunostaining intensity within the VZ-SVZ of the embryonic LGE appeared to decrease from E14.5 to E16.5 (Fig. 1a). Indeed, the fraction of Id1 ${ }^{+}$cells among Sox ${ }^{+}$Ascl1 $^{-}$NPCs declined from E14.5 to E16.5 (Fig. 1b). This down-regulation of Id1 thus precedes the maturation of $S 100 \beta^{+}$acetylated tubulin ${ }^{+}$ependymal cells that takes place after birth ${ }^{24,55}$. To examine further the levels of Id proteins during development, we isolated the VZ-SVZ region of the embryonic LGE and corresponding postnatal basal ganglia and performed immunoblot analysis. The amounts of Id1 and Id 4 declined 
a
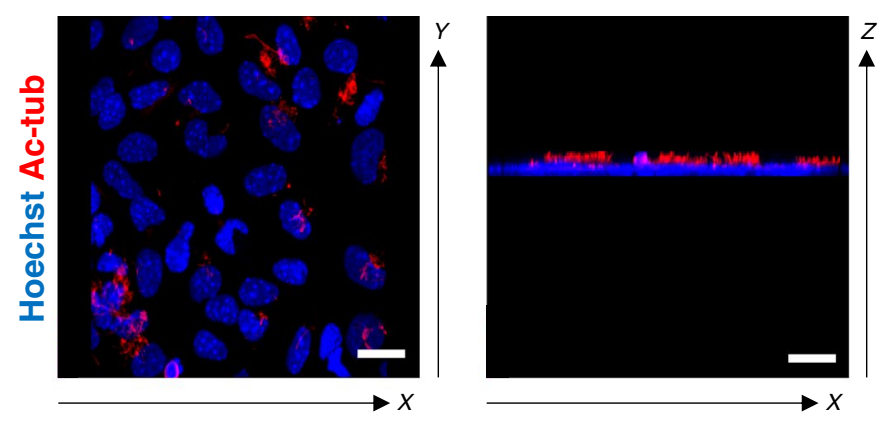

C
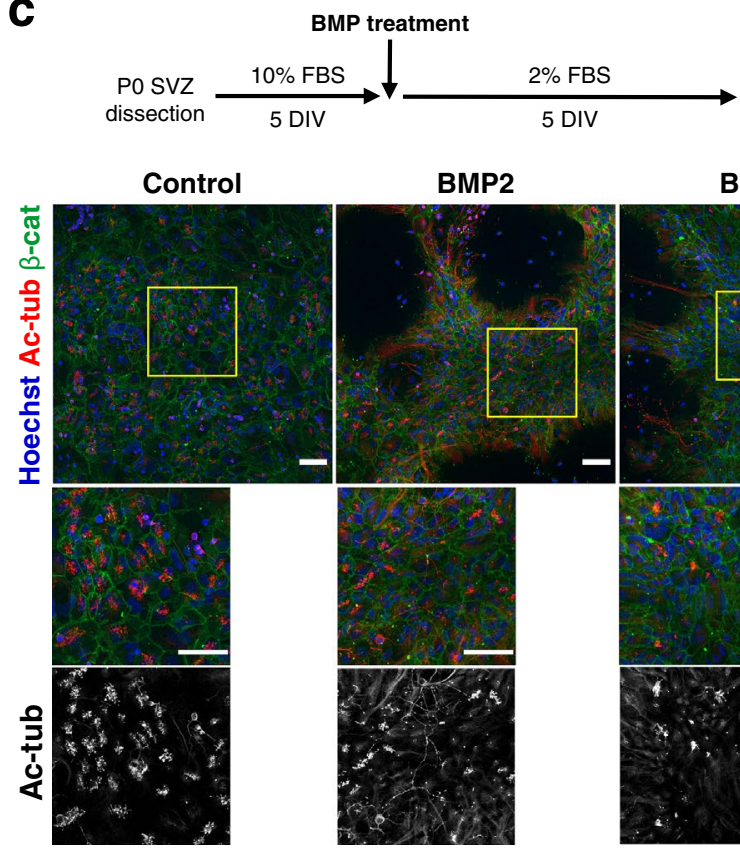

d

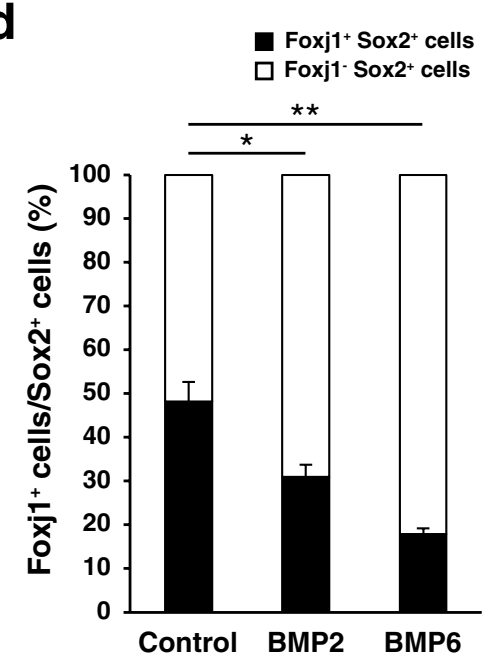

BMP2

BMP6

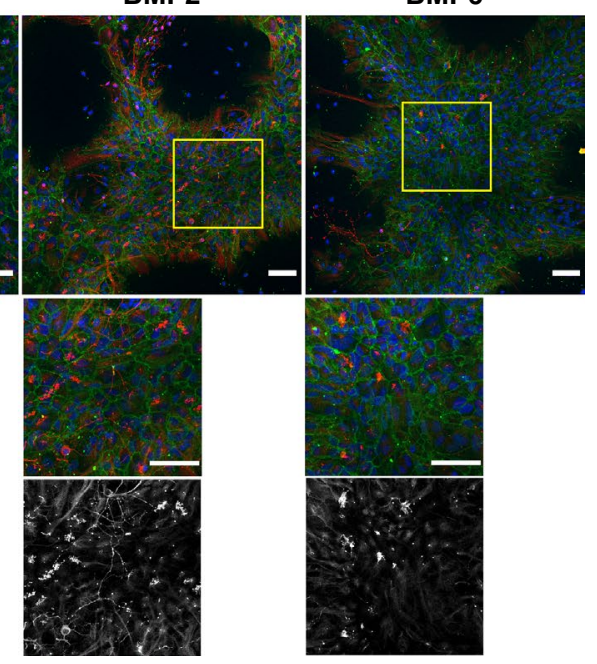

e

Foxj1 b
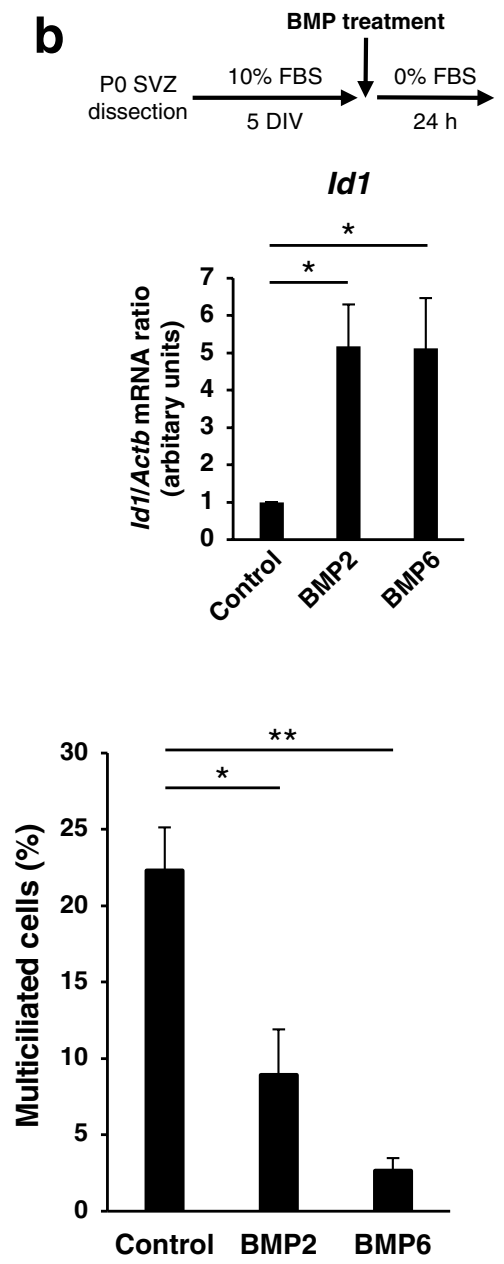

BMP treatment
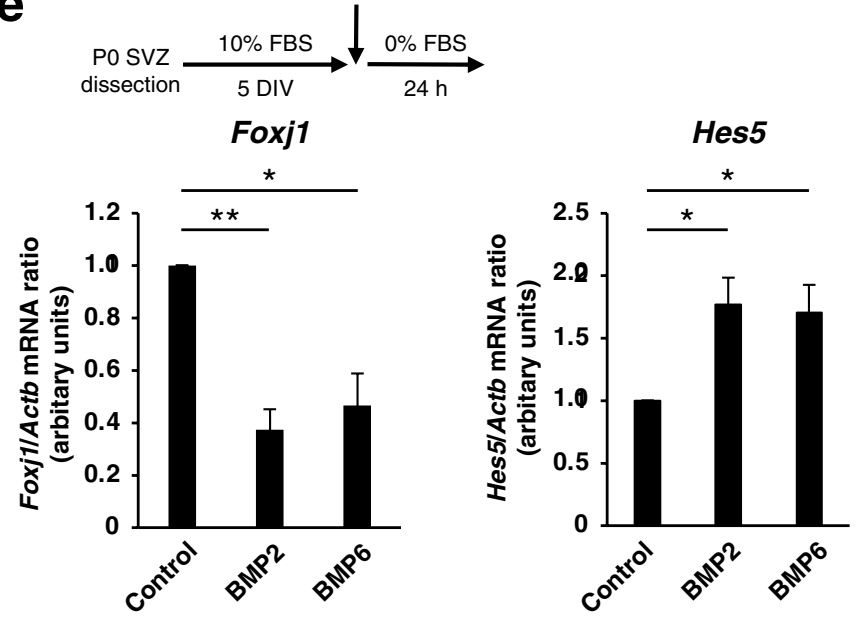
4Figure 2. BMP signaling is sufficient for suppression of ependymal cell differentiation in postnatal NPC cultures. (a) P0 NPC cultures maintained for 5 days in the presence of $10 \%$ FBS and then for 5 days in the $2 \%$ FBS were subjected to immunocytofluorescence staining with antibodies to acetylated tubulin (Ac-tub). Nuclei were counterstained with Hoechst 33342. Immunofluorescence images in the z-projected $x-y$ and $y$-projected $x-z$ planes are shown. Scale bars, $20 \mu \mathrm{m}$. Data are representative of three independent experiments. (b) P0 NPC cultures were maintained for 5 days in the presence of 10\% FBS and then for $24 \mathrm{~h}$ without serum but in the absence (Control) or presence of BMP2 $(50 \mathrm{ng} / \mathrm{ml})$ or BMP6 $(50 \mathrm{ng} / \mathrm{ml})$. The amount of Id1 $\mathrm{mRNA}$ in the cells was then determined by quantitative RT-PCR analysis and normalized by the amount of Actb mRNA. Data are means \pm SEM ( $n=8$ independent experiments). ${ }^{\star} p<0.05$ (Tukey's test). (c) P0 NPC cultures maintained for 5 days in the presence of $10 \%$ FBS and then for 5 days with 2\% FBS in the absence or presence of BMP2 (20 ng/ $\mathrm{ml})$ or BMP6 $(20 \mathrm{ng} / \mathrm{ml})$ were subjected to immunocytofluorescence staining with antibodies to Ac-tub and to $\beta$-catenin ( $\beta$-cat, a marker of adherens juction). Nuclei were counterstained with Hoechst 33342 . The boxed regions of the upper panels are shown at higher magnification in the corresponding middle and lower panels. Scale bars, $50 \mu \mathrm{m}$. Cells with bundles of Ac-tub were counted as multiciliated cells, and their percentage was determined. Data are means \pm SEM ( $\mathrm{n}=3$ independent experiments). ${ }^{\star} p<0.05 ;{ }^{\star \star} p<0.01$ (Tukey's test). (d) Quantification by immunocytofluorescence analysis of Foxj $1^{+}$cells among Sox $2^{+}$NPCs for cultures treated as in (c). Three microscope fields were counted per sample. Total of 300-500 cells were counted per sample. Data are means $\pm \operatorname{SEM}\left(\mathrm{n}=3\right.$ independent experiments). ${ }^{*} p<0.05 ;{ }^{* *} p<0.01$ (Tukey's test). (e) Quantitative RT-PCR analysis of Foxj1 and Hes5 mRNAs for cultures treated as in (b). Data are means \pm SEM $(\mathrm{n}=8$ independent experiments). ${ }^{\star} p<0.05,{ }^{\star *} p<0.01$ (Tukey's test).

between E16 and postnatal day (P) 1, apparently coinciding with the initial induction of Foxj1, a key regulator

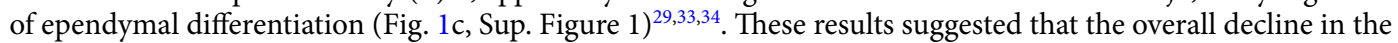
abundance of Id proteins in the VZ-SVZ roughly coincides with the initial differentiation of ependymal cells in the developing basal ganglia.

Given that Id proteins are major effectors of BMP signaling, we asked whether the overall activity of BMP signaling in the VZ-SVZ also changes during development. Immunoblot analysis showed that the abundance of phosphorylated R-Smads (Smad1/5/8) also significantly decreased from E14 to P1 (Fig. 1c, Sup. Figure 1), supporting the notion that a decline in the level of BMP signaling coincides with the initial phase of ependymal differentiation.

We then established cultures of NPCs derived from the lateral ventricular wall at P0 according to a previously described protocol for the study of ependymal differentiation ${ }^{56}$. These NPCs were cultured first in the presence of $10 \%$ fetal bovine serum (FBS) and subsequently in the absence of serum, with serum removal inducing differentiation of the NPCs into multiciliated ependymal cells ${ }^{46,56}$. We found that the amount of Id 1 protein, as well as that of Id4 protein to a lesser extent, in the cultured cells was reduced in response to serum removal, and that this effect appeared to coincide with the initial induction of Foxj1 (Fig. 1d, e, Sup. Figure 1). Moreover, the expression of Id1 and that of Foxj1 appeared to be mutually exclusive (Fig. 1d). Indeed, the intensity of Id1 immunoreactivity was significantly lower in Foxj $1^{+}$cells than in Foxj1- cells at 5 days in vitro (DIV) after serum removal (Fig. 1f), further indicative of a negative correlation between BMP signaling and ependymal differentiation.

BMP ligands suppress ependymal differentiation in postnatal NPC cultures. The removal or a reduction in the concentration of serum in the P0 NPC cultures results in ependymal differentiation over the course of several days, as is apparent from the generation of acetylated tubulin ${ }^{+}$multiciliated cells ${ }^{56}$ (Fig. 2a). Given the apparent negative correlation between BMP signaling and ependymal differentiation, we examined whether BMP signaling actually affects ependymal differentiation by exposing the P0 NPC cultures to BMP2 or BMP6 at the time of serum removal. We confirmed that treatment with BMP2 or BMP6 increased the expression of the downstream target genes $I d 1$ and $I d 4$ (Fig. 2b and data not shown). BMP2 and BMP6 also each significantly reduced both the fraction of multiciliated cells detected at 5 DIV (Fig. 2c) as well as the fraction of Foxj1 ${ }^{+}$ cells (Fig. 2d). Consistent with this result, treatment with BMP2 or BMP6 also resulted in significant downregulation of the amount of Foxj1 mRNA, whereas it significantly increased the expression of the NPC marker gene Hes5 (Fig. 2e). These results thus suggested that BMP signaling suppresses the differentiation of NPCs into ependymal cells in this postnatal NPC culture system.

The reduced proportion of ependymal cells by the treatment with BMPs may be ascribable to its selective effects on proliferation or apoptosis of ependymal precursors. We found, however, that the fraction of cleaved caspase $-3^{+}$cells was very low (less than $5 \%$ ) in this culture and that BMP treatment did not significantly change the proportion of cleaved caspase $-3^{+}$cells in both Foxj $1^{-}$Sox $2^{+}$cells (NPCs) and Foxj $1^{+}$Sox $2^{+}$(ependymal) cells (Sup. Figure 2). Moreover, BMP treatment did not increase, but rather reduced, the fraction of BrdU ${ }^{+}$cells among Foxj $1^{-}$Sox $2^{+}$cells, while having little effects on that among Foxj $1^{+}$Sox $2^{+}$cells (Sup. Figure 3 ). These results support the notion that the reduction of ependymal cells by BMPs is not due to a selective increase of apoptosis or a selective reduction of proliferation of Foxj $1^{+}$ependymal precursors.

A BMPR inhibitor promotes ependymal differentiation in postnatal NPC cultures. We then examined whether BMP signaling is required for ependymal differentiation in this culture system with the use of LDN-193189, an inhibitor of the BMP receptors ALK2 and ALK3. We confirmed that treatment of the NPC cultures with $0.1 \mu \mathrm{M}$ LDN-193189 for $24 \mathrm{~h}$ in the presence of $10 \%$ FBS resulted in down-regulation of Id1 expression (Fig. 3a). Such treatment also increased the level of Foxj1 mRNA (Fig. 3a). Furthermore, treatment with LDN-193189 for 5 days resulted in a significant increase in the fraction of multiciliated cells (Fig. 3b), 


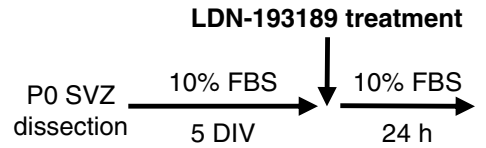

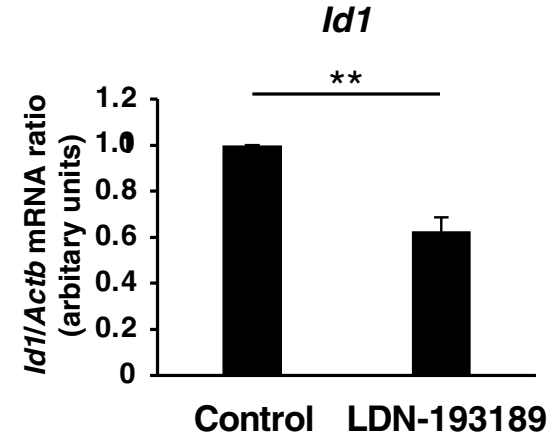

b

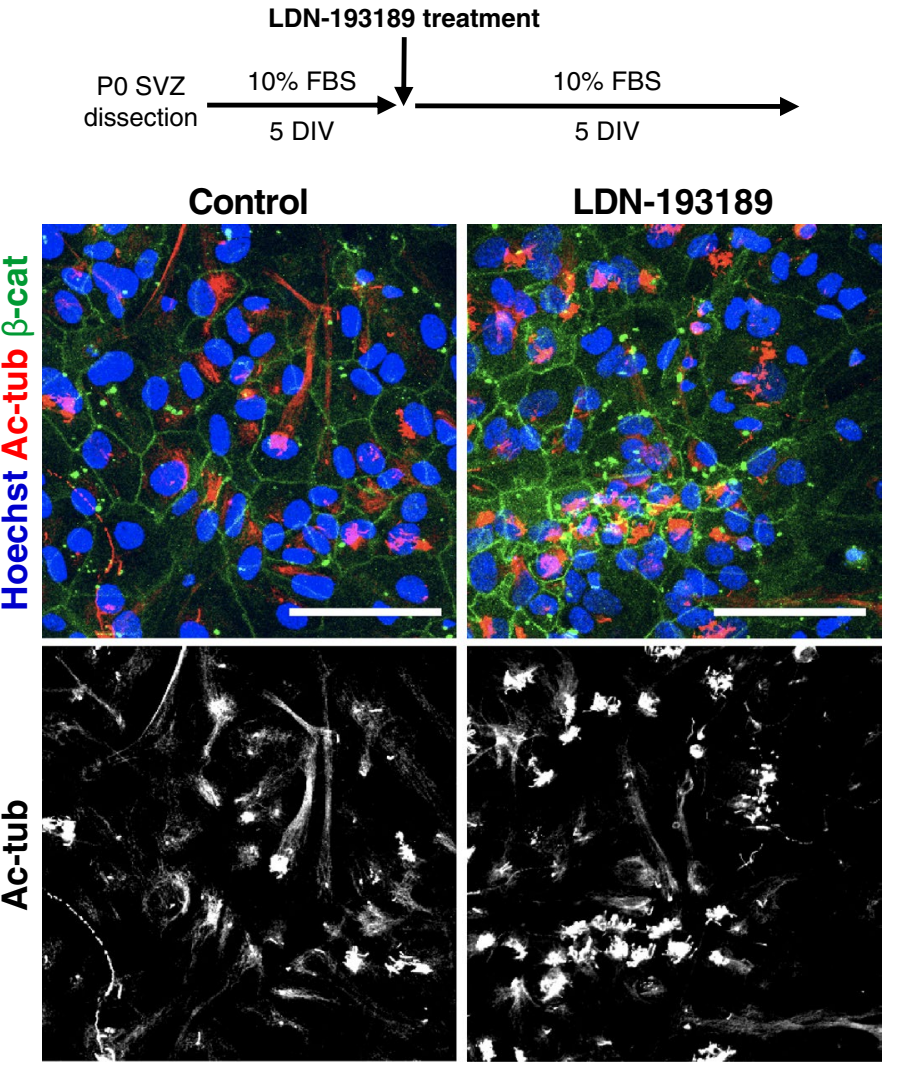

Foxj1

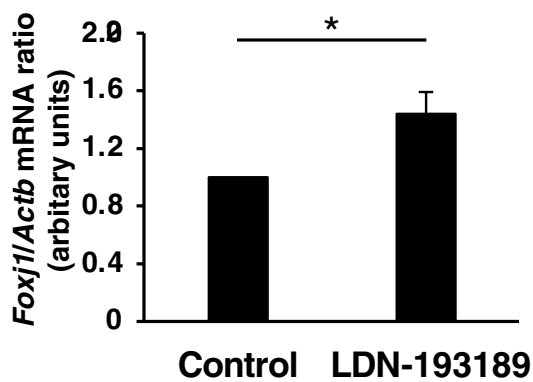

Hes5

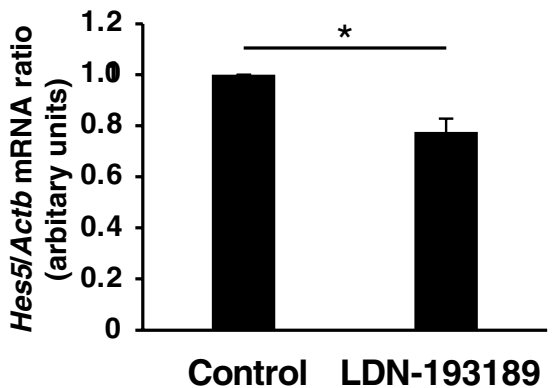

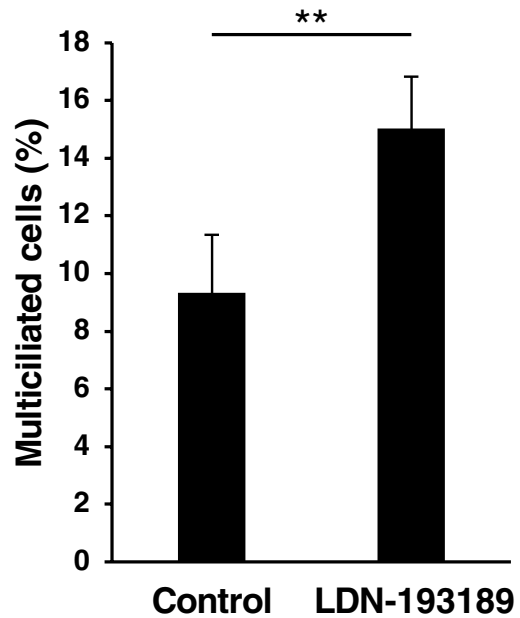

Figure 3. BMP signaling is necessary for suppression of ependymal cell differentiation in postnatal NPC cultures. (a) P0 NPC cultures were maintained for 5 days in the presence of $10 \%$ FBS and then for $24 \mathrm{~h}$ in the additional absence (Control) or presence of LDN-193189 $(0.1 \mu \mathrm{M})$. The amounts of Id1, Foxj1 and Hes5 mRNAs in the cells were then determined by quantitative RT-PCR analysis. Data are means \pm SEM ( $\mathrm{n}=7$ independent experiments). ${ }^{\star} p<0.05$; ${ }^{\star *} p<0.01$ (two-tailed Student's paired $t$ test). (b) P0 NPC cultures maintained for 5 days in the presence of $10 \%$ FBS and then for 5 days in the additional absence or presence of LDN-193189 $(0.1 \mu \mathrm{M})$ were subjected to immunocytofluorescence staining with antibodies to Ac-tub and to $\beta$-cat. Nuclei were counterstained with Hoechst 33342. Scale bars, $50 \mu \mathrm{m}$. Cells with bundles of Ac-tub were counted as multiciliated cells, and their percentage was determined. Three microscope fields were counted per sample. Total of 300-500 cells were counted per sample. Data are means \pm SEM ( $n=3$ independent experiments). ${ }^{*} p<0.01$ (two-tailed Student's paired $t$ test). 
a
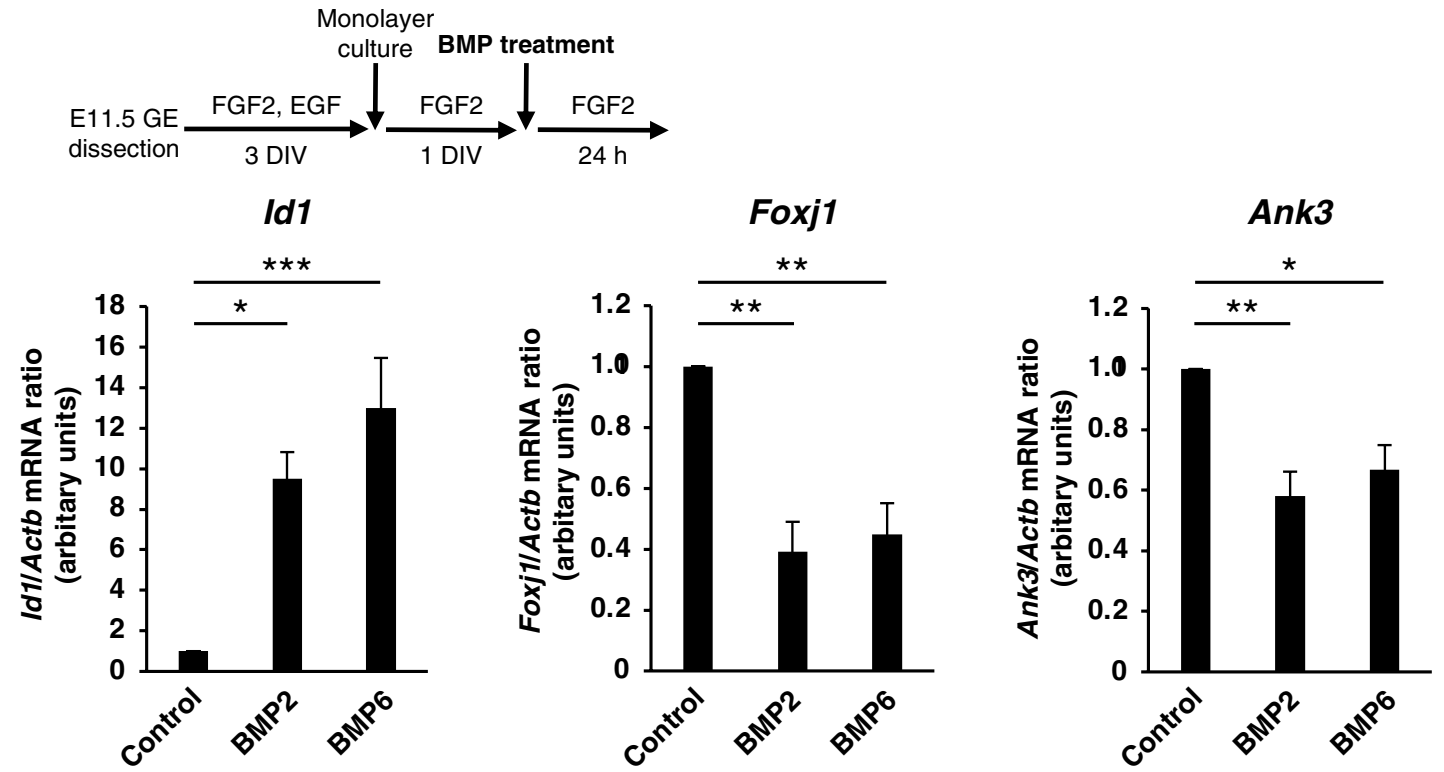

b
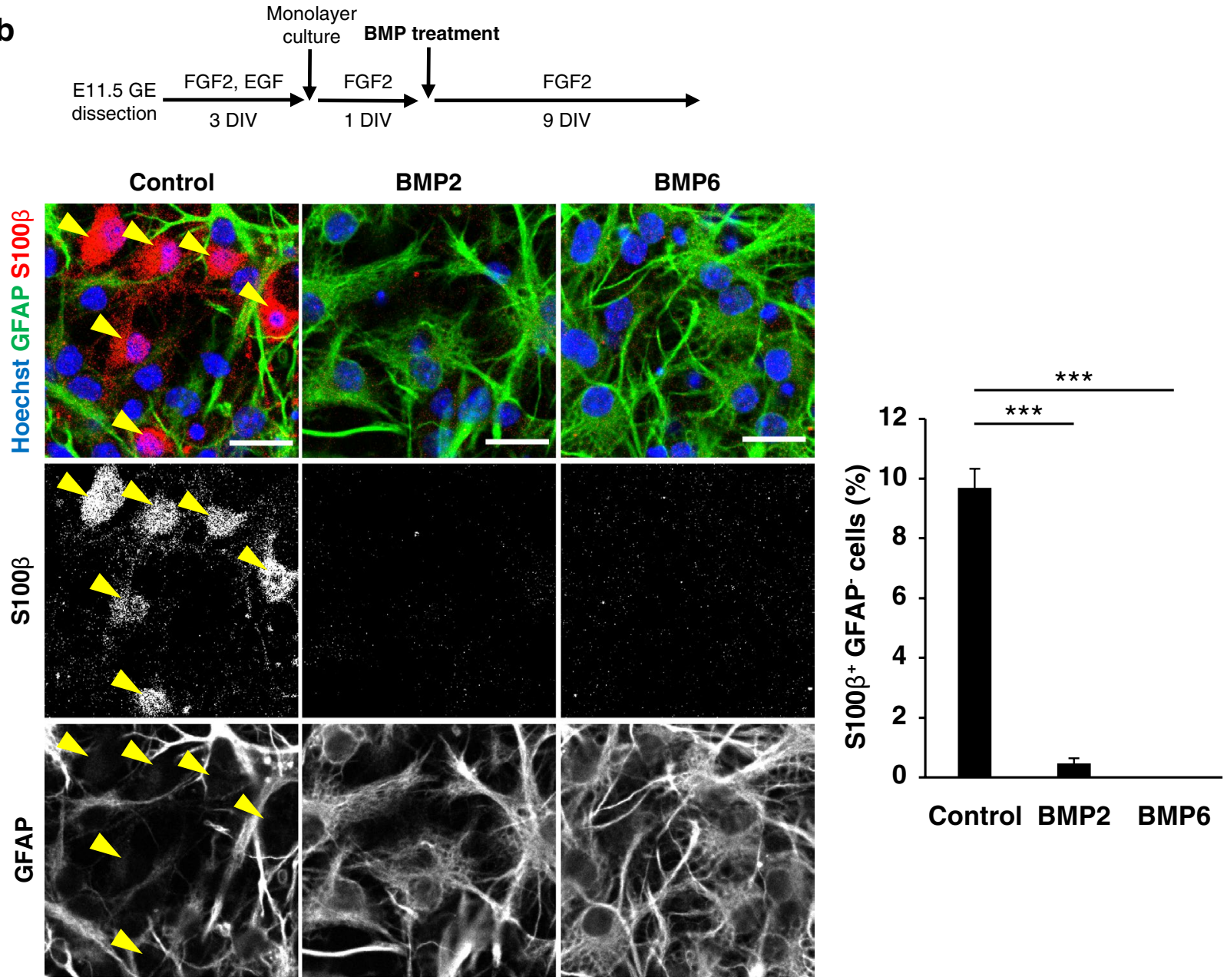

Figure 4. BMP signaling suppresses differentiation of ependymal-like cells among embryonic progenitors. (a) Cells dissociated from the GE of E11.5 embryos were cultured for 3 days in suspension, and the resulting neurospheres were dissociated and cultured as monolayers for 1 day before exposure to BMP2 $(50 \mathrm{ng} / \mathrm{ml})$ or BMP6 $(50 \mathrm{ng} / \mathrm{ml})$ for $24 \mathrm{~h}$. The amounts of Id1, Foxj1 and Ank3 mRNAs in the cells were then determined by quantitative RT-PCR analysis. Data are means \pm SEM ( $\mathrm{n}=3$ independent experiments). ${ }^{*} p<0.05$; ${ }^{* *} p<0.01 ;{ }^{* *} p<0.001$ (Tukey's test). (b) Cultures as in (a) exposed to BMP2 or BMP6 for 9 days (with replenishment of the medium every 2 days) were subjected to immunocytofluorescence staining with antibodies to $S 100 \beta$ and to GFAP. Nuclei were counterstained with Hoechst 33342. Arrowheads indicate S100 $\beta^{+} \mathrm{GFAP}^{-}$ependymal-like cells. Scale bars, $20 \mu \mathrm{m}$. The percentage of S100 $\beta^{+} \mathrm{GFAP}$ cells was determined. Three microscope fields were counted per sample. Total of 200-300 cells were counted per sample. Data are means $\pm \operatorname{SEM}\left(\mathrm{n}=3\right.$ independent experiments). ${ }^{* *} p<0.001$ (Tukey’s test). 
whereas that for $24 \mathrm{~h}$ induced a significant decrease in the expression of Hes5 (Fig. 3a). These results suggested that BMP signaling is necessary for efficient suppression of ependymal differentiation in this postnatal NPC culture system.

BMP ligands suppress ependymal cell-like differentiation in embryonic NPC cultures. The down-regulation of Id proteins apparent in the VZ-SVZ at the late embryonic stage of LGE development (Fig. 1a) prompted us to examine the possible role of BMP signaling in the initial stage of ependymal cell differentiation. We therefore isolated NPCs from the GE at E11.5 and cultured them first for 3 days in suspension and then as monolayers. Exposure of these cells to BMP2 or BMP6 for $24 \mathrm{~h}$ at 1 day after the onset of monolayer culture resulted in a significant decrease in the expression of Foxj1 and Ank3, which encodes an effector of Foxj1 responsible for the lateral adhesion of ependymal cells $s^{56}$, as well as a significant increase in that of Id1 (Fig. 4a). After 10 days of monolayer culture, a fraction of control cells had initiated expression of S100 $\beta$, indicative of ependymal differentiation, without expression of the astrocyte marker GFAP (Fig. 4b). Treatment with BMP2 or BMP6 markedly suppressed this increase in the number of S100 $\beta^{+} \mathrm{GFAP}^{-}$cells (Fig. $4 \mathrm{~b}$ ). These results suggested that BMP signaling suppresses ependymal cell-like differentiation even at an early stage of development equivalent to the perinatal stage. We also observed that exposure of this embryonic NPC culture to BMP2 or BMP6 increased the fraction of $\mathrm{GFAP}^{+}$cells and reduced that of $\mathrm{BrdU}^{+}$cells among Sox $2^{+}$cells (Sup. Figure 4). This is consistent with the previous notion that BMP treatment promotes establishment of "quiescent" NSCs ${ }^{51,57}$, while suppressing ependymal differentiation.

BMP ligands suppress expression of Gemc1 and Mcidas. Given that Geminin family members play a central role in the initial steps of ependymal differentiation, we next asked whether BMP signaling regulates the expression of the corresponding genes. The amount of Mcidas mRNA was significantly reduced by exposure of P0 NPC cultures to BMP2 or BMP6 for $24 \mathrm{~h}$ after serum removal (Fig. 5a). Moreover, the amounts of mRNAs for $M y b$ (which encodes c-Myb) and Trp73 (which encodes TAp73), which act upstream of Foxj1, were also reduced by such BMP treatment (Fig. 5a). Importantly, the expression of Gemc1, which acts upstream of Mcidas, was significantly suppressed by BMP2 or BMP6 (Fig. 5a). Conversely, the levels of Mcidas and Gemc1 mRNAs as well as those of $M y b$ and Trp73 mRNAs were increased by treatment of the cultures with the BMP receptor inhibitor LDN-193189 for $24 \mathrm{~h}$ in the continued presence of serum (Fig. 5b). Together, these results implicated BMP signaling in suppression of the key initial regulators of ependymal cell differentiation.

\section{Discussion}

Although the transcriptional network that governs multiciliated cell differentiation in various organs has been well characterized, it has remained unclear how extrinsic signals regulate this network in the niche that supports ependymal cell specification and differentiation during telencephalic development. Here we show that BMP signaling suppresses the differentiation of mouse GE-derived NPCs into ependymal cells. We thus detected a reduction in the level of BMP signaling (as indicated by the abundance of phosphorylated Smad1/5/8 and of Id proteins) in the VZ-SVZ of the lateral ventricles that coincided with the initial specification and differentiation of ependymal cells. Mutually exclusive expression patterns of Id1 and Foxj1 in NPC cultures also supported a negative role for BMP signaling in ependymal specification. Indeed, we found that BMP signaling suppressed the expression of Gemc1, a key regulator of ependymal specification, as well as that of Mcidas and Foxj1, master regulators of ependymal differentiation (basal body amplification). These results implicate BMP signaling in negative regulation of the specification and differentiation of ependymal cells in the embryonic GE and early postnatal basal ganglia of the mouse telencephalon. BMP signaling has previously been shown to negatively regulate the differentiation of multiciliated cells in the mucociliary epithelium of airways as well as in embryonic stem cell cultures ${ }^{58,59}$, although the molecular mechanisms underlying this regulation remain unclear. It would thus be of interest to investigate whether BMP signaling plays a similar role in suppression of Gemc1 and Mcidas expression in the differentiation of other multiciliated cells.

Possible sources of BMP ligands in the regulation of NPCs include CSF, blood vessels, and NPCs themselves. The mouse choroid plexus, which releases factors into CSF, expresses BMP ligands including BMP2, BMP4, $\mathrm{BMP} 5$, and $\mathrm{BMP}^{5,60}$. A proteomics analysis detected the presence of BMP6 and BMP7 in human CSF ${ }^{61}$. Endothelial cells also express BMP2 and BMP4 ${ }^{62}$, and NPCs in the LGE express BMP6 at the late embryonic stage (data not shown). It is thus plausible that NPCs are exposed to BMP ligands in the VZ-SVZ of the developing LGE. How then do NPCs escape from these BMP ligands in order to differentiate into ependymal cells? More specifically, what mechanisms may underlie the decline in the level of BMP signaling we detected at the VZ-SVZ of the lateral ventricles when NPCs differentiate into ependymal cells? One such mechanism may involve the secretion of BMP inhibitor proteins such as Noggin and low density lipoprotein-related protein 2 (LRP2), both of which are expressed in adult ependymal cells and antagonize the effects of BMP ligands so as to allow the activation of NSCs and the production of neurons in the adult SVZ ${ }^{19,63}$. The expression of Noggin or LRP2 in a subpopulation of embryonic NPCs may support the formation of a niche in which BMP signaling is locally suppressed so as to promote ependymal specification and differentiation.

Ependymal cells and adult NSCs have recently been shown to share a common embryonic origin, with GemC1 and Geminin being respective determinants of these lineages ${ }^{28}$. It remains unknown, however, how the $\mathrm{GemC1}^{+}$ ependymal lineage and the Geminin ${ }^{+}$adult NSC lineage are segregated from common NPCs during development. Given that we now show that BMP signaling inhibits Gemc1 expression in NPCs, BMP signaling might control this bifurcation process, although this hypothesis should be proven by clonal analyses of NPCs in future studies. If this is the case, it would be of interest to investigate how differential sensitivity to BMP ligands might 
a
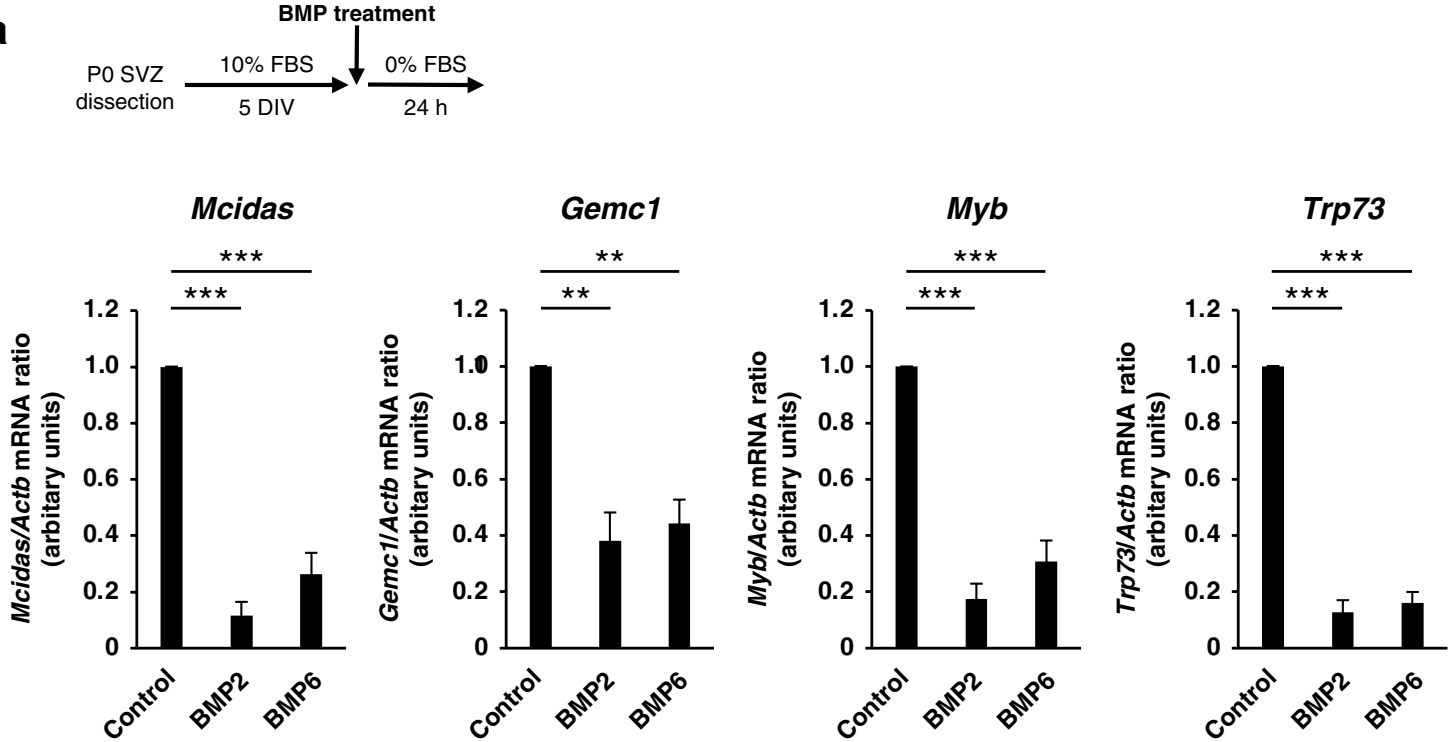

b

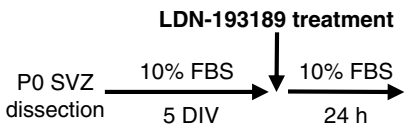

Mcidas

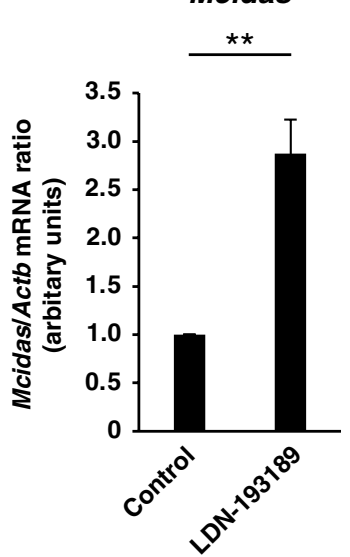

Gemc1

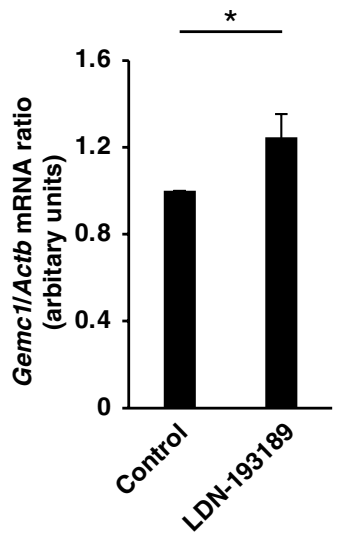

Myb

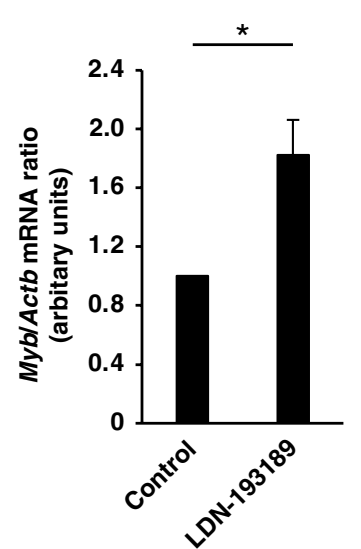

Trp73

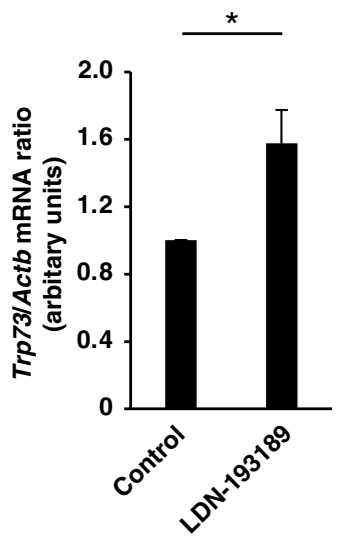

Figure 5. BMP signaling suppresses the expression of initial key regulators of ependymal cell differentiation. (a) P0 NPC cultures maintained for 5 days in the presence of $10 \%$ FBS and then for $24 \mathrm{~h}$ in serum-free medium containing BMP2 $(50 \mathrm{ng} / \mathrm{ml})$ or BMP6 $(50 \mathrm{ng} / \mathrm{ml})$ were subjected to quantitative RT-PCR analysis for determination of the amounts of Mcidas, Gemc1, Myb, and Trp73 mRNAs. Data are means \pm SEM ( $\mathrm{n}=8$ independent experiments). ${ }^{* *} p<0.01,{ }^{* *} p<0.001$ (Tukey's test). (b) P0 NPC cultures maintained for 5 days in the presence of $10 \% \mathrm{FBS}$ and then for $24 \mathrm{~h}$ in the additional absence or presence of LDN-193189 $(0.1 \mu \mathrm{M})$ were analyzed as in (a). Data are means $\pm \operatorname{SEM}\left(\mathrm{n}=7,10,7\right.$, or 6 independent experiments, respectively). ${ }^{\star} p<0.05$; ${ }^{* *} p<0.01$ (two-tailed Student's paired $t$ test). 
emerge among NPCs. For instance, differential expression of BMP inhibitors or BMP signaling components might underlie segregation between ependymal and adult NSC lineages.

What might be the direct target (or targets) of BMP signaling in the regulation of ependymal differentiation? Given that the Gemc1 locus contains multiple Smad binding elements (SBEs), and that ChIP Atlas data indicate that Smad4 binds to this locus in mouse NS5 neural stem cells ${ }^{64}$, it is possible that Gemc1 is a direct target of activated Smad proteins in the BMP signaling pathway, although R-Smads usually function as positive regulators of transcription. Alternatively, Id proteins (effectors of Smad proteins and negative regulators of transcription) may regulate genes related to ependymal differentiation, in which case, given their roles in adult NSC maintenance ${ }^{52-54}$, Id proteins may act at the lineage bifurcation between ependymal cells and adult NSCs.

Ependymal cells and postnatal-adult NSCs form a distinct pinwheel structure at the ventricular surface after their differentiation from NPCs ${ }^{17}$. Of note in this regard, BMP treatment of postnatal NPC cultures reproducibly induced marked changes in cellular architecture that generated gaps in the monolayer culture (Fig. 2c, lower magnification images). This effect may be due to differential lateral cell adhesion ${ }^{56}$ and the sorting of ependymal cells and other cell types induced by the addition of BMP ligands. In addition, reorganization of ECM might contribute to this process, given that dystroglycan-mediated ECM reorganization promotes postnatal maturation of ependymal cells (in part through control of Notch signaling and Mcidas and Foxj1 expression) ${ }^{20,47}$. It would thus be of interest to investigate how ECM reorganization and BMP signaling might interact during ependymal differentiation and formation of the pinwheel structure at the ventricular wall.

In conclusion, we have here uncovered a previously unappreciated role of BMP signaling in suppression of ependymal differentiation from NPCs, with this function of BMP signaling likely being mediated through regulation of the expression of the Geminin family members GemC1 and Mcidas as well as that of Foxj1. Abnormal ependymal differentiation is associated with brain malformation and disorders such as hydrocephalus ${ }^{2,6-13,65-67}$. Of interest, mice lacking the $M s x$ gene, an established downstream target of BMP signaling in other systems, also develop hydrocephalus ${ }^{59}$. Our findings may thus provide insight into the development of such ependymal cell-related disorders.

\section{Experimental procedures}

Ethics statement. All animals were maintained and studied according to protocols approved by the Animal Care and Use Committee of The University of Tokyo (approval numbers: P25-8, P25-27, PH27-3 and P304). All procedures were followed in accordance with the University of Tokyo guidelines for the care and use of laboratory animals.

Animals. Slc:ICR (ICR) and C57BL/6NCrSlc (B6J) mice were obtained from SLC Japan and were maintained in a temperature $\left(20-26^{\circ} \mathrm{C}\right)$ - and relative humidity $(35-65 \%)$-controlled environment with a normal 12-h-light,12-h-dark cycle. They were housed two to six per sterile cage (Innocage, Innovive) containing bedding chips (Palsoft, Oriental Yeast) and were provided with irradiated food (CE2, CLEA Japan) and filtered water ad libitum. Mouse embryos were isolated at various ages, with E0.5 being considered the time of vaginal plug appearance.

Postnatal NPC culture. The differentiation of ependymal cells from isolated postnatal NPCs in culture was studied according to a modified version of a method described previously ${ }^{56}$. The lateral ventricular wall was dissected from Slc:ICR mice at P0, when NPCs are still bipotent that can produce both ependymal cells and glial cells $^{27,29}$. Dissociated cells were transferred to poly-D-lysine (Sigma-Aldrich)-coated 24 well plate and cultured at a density of $1 \times 10^{6}$ cells $/ \mathrm{ml}$ in a proliferation medium consisting of Dulbecco's modified Eagle's medium containing high glucose (DMEM-High Glucose 4.5, Gibco) and supplemented with 10\% FBS (Gibco) and 1\% penicillin-streptomycin (Invitrogen). After culture for 5 days, the medium was switched to a differentiation medium (proliferation medium containing $0 \%$ or $2 \%$ FBS) supplemented (or not) with recombinant human/ mouse/rat BMP2 or mouse BMP6 (R \& D Systems) at $20 \mathrm{ng} / \mathrm{ml}$ or $50 \mathrm{ng} / \mathrm{ml}$. BMP2 and BMP6 were dissolved in a solution containing $4 \mathrm{mM} \mathrm{HCl}$ and $0.1 \%$ bovine serum albumin, which was also used as a vehicle control. Alternatively, after culture for 5 days in proliferation medium, the cells were exposed to LDN-193189 (SigmaAldrich) at $0.1 \mu \mathrm{M}$ in proliferation medium. LDN-193189 was dissolved in distilled water. For cell proliferation analysis, $10 \mu \mathrm{M}$ 5-Bromo-2' -Deoxyuridine (BrdU, Invitrogen) was administered to the culture $2 \mathrm{~h}$ before sample collection.

Embryonic NPC culture. Primary NPCs were isolated from the GE of Slc:ICR mouse embryos at E11.5. The dissected tissue was subjected to enzymatic digestion with a papain-based solution (Sumitomo Bakelite), and the dissociated cells were cultured in DMEM-F12 (1:1, v/v) (Gibco) supplemented with B27 (Invitrogen), recombinant human fibroblast growth factor 2 (FGF2, $20 \mathrm{ng} / \mathrm{ml}$ ) (Invitrogen) and recombinant human epidermal growth factor (EGF, $20 \mathrm{ng} / \mathrm{ml}$ ) (Invitrogen). For cell proliferation analysis, $10 \mu \mathrm{M}$ BrdU (Invitrogen) was administered to the culture $2 \mathrm{~h}$ before sample collection.

Quantitative RT-PCR analysis. Total RNA was isolated from cell cultures with the use of RNAiso Plus (Takara), and portions ( $1 \mu \mathrm{g})$ of the RNA were subjected to RT with ReverTra Ace qPCR RT Master Mix with gDNA Remover (Toyobo). The resulting cDNA was subjected to real-time PCR analysis in a LightCycler 480 instrument (Roche) with KAPA SYBR fast qPCR Mix (Toyobo). Primer sequences $\left(5^{\prime} \rightarrow 3^{\prime}\right.$, and forward and reverse, respectively) were as follows: $A c t b$, ATAGTCATTCCAAGTATCCATGAAA and GCGACCATCCTC CTCTTAG; Foxj1, GGGCGAAATGGTCTCTAAG and GTCAGGCTGGAAGGTTTGTA; Id1, TACGACATG AACGGCTGCTA and TCTCCACCTTGCTCACTTT; Gemc1, TGGTCTCCTGGACAACACTG and TAACTC 
AGAGGGCGATTCCA; Mcidas, AACCGAAGCGTCTCCTAGTG and GGTCATCCATTGCATCTCTG; Ank3, CATCCTAAACTTCAAGTCCACACTATAA and AACTCACACAGTGGTGGTAA; Trp73, GCACCTACT TTGACCTCCCC and GCACTGCTGAGCAAATTGAAC; $M y b$, CTTGCAGCTCAAGAAATTAAATACG and ATCCGATTCCTGCTTAATCAC; and Hes5, AAGTGACTTCTGCGAAGTT and AAGTCCTCTACGGGCTG.

Immunocytofluorescence analysis. Immunocytofluorescence analysis was performed as described previously ${ }^{68}$. Cells were fixed with $4 \%$ paraformaldehyde in phosphate buffered-saline (PBS), permeabilized for 10 min with $0.2 \%$ Triton X-100 in PBS, exposed for 30 min to $3 \%$ bovine serum albumin in PBS (blocking solution), incubated first overnight at $4{ }^{\circ} \mathrm{C}$ with primary antibodies diluted in the blocking solution and then for $1 \mathrm{~h}$ at room temperature with Alexa Fluor-labeled secondary antibodies (1:1000 dilution) (A21206, A21202, A11039, A31572, A31570, A31571, A31573, A32795, A21447, Molecular Probes) and Hoechst 33342 (1:1000 dilution) (Molecular Probes) in blocking solution, and then mounted in Mowiol (Calbiochem). Primary antibodies and their dilutions were as follows: anti-acetylated $\alpha$-tubulin, 1:500 (T6793, Sigma-Aldrich); anti-Id1, 1:500 (BCH-1/37-2, Biocheck); anti- $\beta$-catenin, 1:200 (C2206, Sigma-Aldrich); anti-Foxj1, 1:500 (14-9965, eBioscience); anti-Sox2, 1:200 (sc-17320, Santa Cruz); anti-S100ß, 1:200 (S2657-0.2ML, Sigma-Aldrich); anti-BrdU, 1:500 (ab6326, Abcam); anti-cleaved caspase3, 1:500 (9664S, Cell Signaling Technology); and anti-GFAP, 1:1000 (ab4674, Abcam). Images were acquired with a laser-scanning confocal microscope (TSC-SP5, Leica or LSM 880 , Zeiss) and processed with ImageJ software (NIH).

Immunohistofluorescence analysis. Immunohistofluorescence analysis was performed as described previously ${ }^{69}$. Adult (P56-P63) B6J mice were subjected to perfusion fixation with 4\% paraformaldehyde in PBS, and the brain was dissected and fixed for $24 \mathrm{~h}$ with the same solution. E14.5 or E16.5 B6J embryos were fixed for $2 \mathrm{~h}$ with the same fixative. The isolated brain subjected to cryoprotection with sucrose and embedded and frozen in OCT compound (Tissue TEK). Sections prepared at a thickness of 10-12 $\mu \mathrm{m}$ were exposed to $0.1 \%$ Triton X-100 and 3\% bovine serum albumin in Tris-buffered saline (blocking solution) for $1 \mathrm{~h}$ at room temperature before incubation first overnight at $4{ }^{\circ} \mathrm{C}$ with primary antibodies diluted in blocking solution and then for $1 \mathrm{~h}$ at room temperature with Alexa Fluor-labeled secondary antibodies (1:1000 dilution) (A11055, A11039, A31572, A31570, A31571, A21447, Molecular Probes) and Hoechst 33342 (1:1000 dilution) (Molecular Probes) also diluted in blocking solution. They were finally mounted in Mowiol (Calbiochem) for imaging with a laser-scanning confocal microscope (LSM 880, Zeiss), and images were processed with ImageJ software (NIH). Primary antibodies and their dilutions were as follows: anti-Id1, 1:500 (BCH-1/37-2, Biocheck); anti-Id4, 1:500 (BCH-9/82-12, Biocheck); anti-S100, 1:200 (ab4066 4C4.9, Abcam); anti-GFAP, 1:1000 (ab4674, Abcam); antiSox2, 1:200 (sc-17320, Santa Cruz); and anti-Ascl1, 1:200 (556604, BD Pharmingen).

Immunoblot analysis. Immunoblot analysis was performed as described previously ${ }^{70}$. Brain tissue or cultured cells were lysed with a solution containing $50 \mathrm{mM}$ Tris- $\mathrm{HCl}$ (pH 7.5), $150 \mathrm{mM} \mathrm{NaCl}, 1 \% \mathrm{NP}-40,1 \mathrm{mM}$ EDTA, $0.1 \%$ sodium deoxycholate, $0.1 \%$ SDS, $1 \mathrm{mM}$ dithiothreitol, and aprotinin $(1 \mathrm{mg} / \mathrm{ml})$. Phosphatase inhibitor (PHOSS-RO, Sigma-Aldrich) was added to the solution according to the manufacture's instruction. The protein concentration of the lysates was determined with a Pierce BCA Protein Assay Kit (Thermo Fisher Scientific). Protein samples $(\sim 10 \mu \mathrm{g})$ were fractionated by SDS-polyacrylamide gel electrophoresis on a $8-16 \%$ gel (Biorad) and the separated proteins were transferred to a polyvinylidene difluoride membrane (Millipore), which was then exposed for $1 \mathrm{~h}$ at room temperature to $2 \%$ dried nonfat milk before incubation overnight at $4{ }^{\circ} \mathrm{C}$ with antibodies to phospho-Smad1/5/8 (D5B10, Cell Signaling Technology, 1:500), to Id1 (BCH-1/37-2, Biocheck, 1:500), to Id4 (BCH-9/82-12, Biocheck, 1:500), to Foxj1 (HPA005714, Sigma-Aldrich, 1:500) or to GAPDH (MAB374, Sigma-Aldrich, 1:2000). The membrane was then incubated for $1 \mathrm{~h}$ at room temperature with horseradish peroxidase-conjugated secondary antibodies (GE Healthcare), after which immune complexes were detected with a chemiluminescence reagent $[100 \mathrm{mM}$ Tris- $\mathrm{HCl}(\mathrm{pH} 8.5), 1.25 \mathrm{mM}$ luminol, $0.2 \mathrm{mM}$ coumaric acid, $0.009 \% \mathrm{H}_{2} \mathrm{O}_{2}$ or Super Signal West Atto Ultimate Sensitivity Substrate (Thermo Fisher Scientific)]. The images were acquired by Fusion instrument (M\&S Instrument Inc.) and quantified using Evolution Capt software (M\&S Instrument Inc).

Statistical analysis. Quantitative data are presented as means \pm SEM and were compared either among multiple groups with one-way analysis of variance followed by Tukey's post hoc test or between two groups with the two-tailed Student's paired or unpaired $t$ test. A $p$ value of $<0.05$ was considered statistically significant. The number of animals in each experiment is stated in the respective figure legends.

Received: 20 February 2020; Accepted: 18 November 2020

Published online: 12 January 2021

\section{References}

1. Del Bigio, M. R. The ependyma: a protective barrier between brain and cerebrospinal fluid. Glia 14, 1-13 (1995).

2. Del Bigio, M. R. Ependymal cells: biology and pathology. Acta Neuropathol. 119, 55-73 (2010).

3. Spassky, N. \& Meunier, A. The development and functions of multiciliated epithelia. Nat. Rev. Mol. Cell Biol. 18, 423-436 (2017).

4. Dani, N. \& Lehtinen, M. K. CSF makes waves in the neural stem cell niche. Cell Stem Cell 19, 565-566 (2016). 
5. Silva-Vargas, V., Maldonado-Soto, A. R., Mizrak, D., Codega, P. \& Doetsch, F. Age-dependent niche signals from the choroid plexus regulate adult neural stem cells. Cell Stem Cell 19, 643-652 (2016).

6. Tissir, F. et al. Lack of cadherins Celsr2 and Celsr3 impairs ependymal ciliogenesis, leading to fatal hydrocephalus. Nat. Neurosci. 13, 700-707 (2010).

7. Banizs, B. et al. Dysfunctional cilia lead to altered ependyma and choroid plexus function, and result in the formation of hydrocephalus. Development 132, 5329-5339 (2005).

8. Domínguez-Pinos, M. D. et al. Ependymal denudation and alterations of the subventricular zone occur in human fetuses with a moderate communicating hydrocephalus. J. Neuropathol. Exp. Neurol. 64, 595-604 (2005).

9. Ibañez-Tallon, I. et al. Dysfunction of axonemal dynein heavy chain Mdnah5 inhibits ependymanl flow and reveals a novel mechanism for hydrocephalus formation. Hum. Mol. Genet. 13, 2133-2141 (2004).

10. Wagner, C. et al. Cellular mechanisms involved in the stenosis and obliteration of the cerebral aqueduct of hyh mutant mice developing congenital hydrocephalus. J. Neuropathol. Exp. Neurol. 62, 1019-1040 (2003).

11. Lee, J. E. \& Gleeson, J. G. Cilia in the nervous system: linking cilia function and neurodevelopmental disorders. Curr. Opin. Neurol. 24, 98-105 (2011).

12. Marley, A. \& von Zastrow, M. A simple cell-based assay reveals that diverse neuropsychiatric risk genes converge on primary cilia. PLoS ONE 7, e46647 (2012).

13. Brandler, W. M. \& Paracchini, S. The genetic relationship between handedness and neurodevelopmental disorders. Trends Mol Med 20, 83-90 (2014).

14. Doetsch, F. \& Alvarez-Buylla, A. Network of tangential pathways for neuronal migration in adult mammalian brain. Proc. Natl. Acad. Sci. U. S. A. 93, 14895-14900 (1996).

15. Doetsch, F., Caille, I., Lim, D. A., Garcia-Verdugo, J. M. \& Alvarez-Buylla, A. Subventricular zone astrocytes are neural stem cells in the adult mammalian brain. Cell 97, 703-716 (1999).

16. Lim, D. \& Alvarez-Buylla, A. The adult ventricular-subventricular zone and olfactory bulb neurogenesis. Cold Spring Harb. Perspect. Biol. 8, a018820 (2016).

17. Mirzadeh, Z., Merkle, F. T., Soriano-Navarro, M., Garcia-Verdugo, J. M. \& Alvarez-Buylla, A. Neural stem cells confer unique pinwheel architecture to the ventricular surface in neurogenic regions of the adult brain. Cell Stem Cell 3, 265-278 (2008).

18. Alvarez-Buylla, A. \& Lim, D. A. For the long run: maintaining germinal niches in the adult brain. Neuron 41, 683-686 (2004).

19. Lim, D. A. et al. Noggin antagonizes BMP signaling to create a niche for adult neurogenesis. Neuron 28, $713-726$ (2000).

20. Nascimento, M. A., Sorokin, L. \& Coelho-Sampaio, T. Fractone bulbs derive from ependymal cells and their laminin composition influence the stem cell niche in the subventricular zone. J. Neurosci. 38, 3064-3117 (2018).

21. Stumm, R. K. et al. A dual role for the SDF-1/CXCR4 chemokine receptor system in adult brain: Isoform-selective regulation of SDF-1 expression modulates CXCR4-dependent neuronal plasticity and cerebral leukocyte recruitment after focal ischemia. J. Neurosci. 22, 5865-5878 (2002).

22. Sawamoto, K. et al. New neurons follow the flow of cerebrospinal fluid in the adult brain. Science 311, 629-632 (2006).

23. Petrik, D. et al. Epithelial sodium channel regulates adult neural stem cell proliferation in a flow-dependent manner. Cell Stem Cell 22, 865-878.e8 (2018).

24. Spassky, N. et al. Adult ependymal cells are postmitotic and are derived from radial glial cells during embryogenesis. J. Neurosci. 25, 10-18 (2005).

25. Furutachi, S. et al. Slowly dividing neural progenitors are an embryonic origin of adult neural stem cells. Nat. Neurosci. 18, 657-665 (2015).

26. Fuentealba, L. C. et al. Embryonic origin of postnatal neural stem cells. Cell 161, 1644-1655 (2015).

27. Redmond, S. A. et al. Development of ependymal and postnatal neural stem cells and their origin from a common embryonic progenitor. Cell Rep. 27, 429-441.e3 (2019).

28. Ortiz-Álvarez, G. et al. Adult neural stem cells and multiciliated ependymal cells share a common lineage regulated by the geminin family members. Neuron 102, 159-172 (2019).

29. Jacquet, B. V. et al. FoxJ1-dependent gene expression is required for differentiation of radial glia into ependymal cells and a subset of astrocytes in the postnatal brain. Development 136, 4021-4031 (2009).

30. Malaterre, J. et al. c-Myb is required for neural progenitor cell proliferation and maintenance of the neural stem cell niche in adult brain. Stem Cells 26, 173-181 (2008).

31. Kyrousi, C. et al. Mcidas and GemC1 are key regulators for the generation of multiciliated ependymal cells in the adult neurogenic niche. Development 142, 3661-3674 (2015).

32. Lalioti, M. E. et al. GemC1 is a critical switch for neural stem cell generation in the postnatal brain. Glia 67, 2360-2373 (2019).

33. Yu, X., Ng, C. P., Habacher, H. \& Roy, S. Foxj1 transcription factors are master regulators of the motile ciliogenic program. Nat. Genet. 40, 1445-1453 (2008).

34. Stubbs, J. L., Oishi, I., Izpisúa Belmonte, J. C. \& Kintner, C. The forkhead protein Foxj1 specifies node-like cilia in Xenopus and zebrafish embryos. Nat. Genet. 40, 1454-1460 (2008).

35. Boon, M. et al. MCIDAS mutations result in a mucociliary clearance disorder with reduced generation of multiple motile cilia. Nat. Commun. 5, 1-8 (2014).

36. Stubbs, J. L., Vladar, E. K., Axelrod, J. D. \& Kintner, C. Multicilin promotes centriole assembly and ciliogenesis during multiciliate cell differentiation. Nat. Cell Biol. 14, 140-147 (2012).

37. Tan, F. E. et al. Myb promotes centriole amplification and later steps of the multiciliogenesis program. Developement 140, 4277-4286 (2013).

38. Arbi, M. et al. GemC1 controls multiciliogenesis in the airway epithelium. EMBO Rep. 17, 400-413 (2016).

39. Terré, B. et al. GEMC 1 is a critical regulator of multiciliated cell differentiation. EMBO J. 35, 942-960 (2016).

40. Fujitani, M., Sato, R. \& Yamashita, T. Loss of p73 in ependymal cells during the perinatal period leads to aqueductal stenosis. Sci. Rep. 7, 1-3 (2017).

41. Gonzalez-Cano, L. et al. p73 is required for ependymal cell maturation and neurogenic SVZ cytoarchitecture. Dev. Neurobiol. 76, 730-747 (2016).

42. Lu, H. et al. Mcidas mutant mice reveal a two-step process for the specification and differentiation of multiciliated cells in mammals. Development 146, dev172643 (2019).

43. Kyrousi, C., Lygerou, Z. \& Taraviras, S. How a radial glial cell decides to become a multiciliated ependymal cell. Glia 65, 1032-1042 (2017).

44. Ma, L., Quigley, I., Omran, H. \& Kintner, C. Multicilin drives centriole biogenesis via E2f proteins. Genes Dev. 28, 1461-1471 (2014).

45. Kim, S., Ma, L., Shokhirev, M. N., Quigley, I. \& Kintner, C. Multicilin and activated E2f4 induce multiciliated cell differentiation in primary fibroblasts. Sci. Rep. 8, 1-14 (2018).

46. Abdi, K. et al. EGFR signaling termination via numb trafficking in ependymal progenitors controls postnatal neurogenic niche differentiation. Cell Rep. 28, 2012-2022.e4 (2019). 
47. McClenahan, F. K., Sharma, H., Shan, X., Eyermann, C. \& Colognato, H. Dystroglycan suppresses notch to regulate stem cell niche structure and function in the developing postnatal subventricular zone. Dev. Cell 38, 548-566 (2016).

48. Tavares, B. et al. Notch/Her12 signalling modulates, motile/immotile cilia ratio downstream of Foxjla in zebrafish left-right organizer. Elife 6, 1-26 (2017).

49. Miyazono, K., Kamiya, Y. \& Morikawa, M. Bone morphogenetic protein receptors and signal transduction. J. Biochem. 147, 35-51 (2010).

50. Hegarty, S. V., O'Keeffe, G. W. \& Sullivan, A. M. BMP-Smad 1/5/8 signalling in the development of the nervous system. Prog. Neurobiol. 109, 28-41 (2013).

51. Mira, H. et al. Signaling through BMPR-IA regulates quiescence and long-term activity of neural stem cells in the adult hippocampus. Cell Stem Cell 7, 78-89 (2010).

52. Nam, H. \& Benezra, R. High levels of Id1 expression define B1 type adult neural stem cells. Cell Stem Cell 5, 515-526 (2009).

53. Blomfield, I. M. et al. Id4 promotes the elimination of the pro-activation factor Ascl1 to maintain quiescence of adult hippocampal stem cells. Elife 8, 1-26 (2019).

54. Zhang, R. et al. Id4 downstream of Notch2 maintains neural stem cell quiescence in the adult hippocampus. Cell Rep. 28, 14851498.e6 (2019).

55. Guirao, B. et al. Coupling between hydrodynamic forces and planar cell polarity orients mammalian motile cilia. Nat. Cell Biol. $12,341-350$ (2010).

56. Paez-Gonzalez, P. et al. Ank3-dependent SVZ niche assembly is required for the continued production of new neurons. Neuron 71, 61-75 (2011)

57. Martynoga, B. et al. Epigenomic enhancer annotation reveals a key role for NFIX in neural stem cell quiescence. Genes Dev. 27, 1769-1786 (2013).

58. Nishimura, Y., Kurisaki, A., Nakanishi, M., Ohnuma, K. \& Ninomiya, N. Biochemical and biophysical research communications inhibitory Smad proteins promote the differentiation of mouse embryonic stem cells into ependymal-like ciliated cells. Biochem. Biophys. Res. Commun. 401, 1-6 (2010).

59. Zhao, S., Chen, Q., Hung, F. C. \& Overbeek, P. A. BMP signaling is required for development of the ciliary body. Development 129, 4435-4442 (2002).

60. Lehtinen, M. K. et al. The cerebrospinal fluid provides a proliferative niche for neural progenitor cells. Neuron 69, 893-905 (2011).

61. Begcevic, I., Brinc, D., Drabovich, A. P., Batruch, I. \& Diamandis, E. P. Identification of brain-enriched proteins in the cerebrospinal fluid proteome by LC-MS/MS profiling and mining of the Human Protein Atlas. Clin. Proteomics 13, 1-13 (2016).

62. Mathieu, C. et al. Endothelial cell-derived bone morphogenetic proteins control proliferation of neural stem/progenitor cells. Mol. Cell. Neurosci. 38, 569-577 (2008).

63. Gajera, C. R. et al. LRP2 in ependymal cells regulates BMP signaling in the adult neurogenic niche. J. Cell Sci. 123, 1922-1930 (2010).

64. Moen, M. J. et al. An interaction network of mental disorder proteins in neural stem cells. Transl. Psychiatry 7, e1082 (2017).

65. Tissir, F. \& Goffinet, A. M. Shaping the nervous system: role of the core planar cell polarity genes. Nat. Rev. Neurosci. 14, 525-535 (2013).

66. Mirzadeh, Z., Han, Y.-G., Soriano-Navarro, M., Garcia-Verdugo, J. M. \& Alvarez-Buylla, A. Cilia organize ependymal planar polarity. J. Neurosci. 30, 2600-2610 (2010).

67. Abdi, K. et al. Uncovering inherent cellular plasticity of multiciliated ependyma leading to ventricular wall transformation and hydrocephalus. Nat. Commun. 9, 1-16 (2018).

68. Sakai, H. et al. Plag1 regulates neuronal gene expression and neuronal differentiation of neocortical neural progenitor cells. Genes Cells 24, 650-666 (2019)

69. Mitsui, Y. et al. Inactivation of bone morphogenetic protein 2 may predict clinical outcome and poor overall survival for renal cell carcinoma through epigenetic pathways. Oncotarget 6, 9577 (2015).

70. Okazaki, T. et al. The ASK family kinases differentially mediate induction of type I interferon and apoptosis during the antiviral response. Sci. Signal. 8, 1-13 (2015).

\section{Acknowledgements}

We thank members of the Gotoh laboratory for discussion. This study was supported by KAKENHI grants from the Ministry of Education, Culture, Sports, Science, and Technology of Japan and the Japan Society for the Promotion of Science (JP18J22995 to S.Y.; JP18K06477 to D.K.; JP16H06481, JP16H06279, JP16H06479, and JP15H05773 to Y.G.) as well as by AMED-CREST of the Japan Agency for Medical Research and Development (JP19gm0610013 and JP19gm1310004), by the Uehara Memorial Foundation, and by the International Research Center for Neurointelligence (WPI-IRCN), The University of Tokyo Institutes for Advanced Study.

\section{Author contributions}

H.O.: conception and design, collection and assembly of data, data analysis and interpretation, manuscript writing. S.Y.: conception and design, data interpretation, manuscript writing. T.W.: conception and design. T.K.: data interpretation, supervision. Y.H.: data interpretation, supervision. D.K.: data interpretation, funding acquisition, supervision. Y.G.: conception and design, data interpretation, financial support, administrative support, supervision, manuscript writing, final approval of manuscript.

\section{Competing interests}

The authors declare no competing interests.

\section{Additional information}

Supplementary Information The online version contains supplementary material available at https://doi. org/10.1038/s41598-020-79610-6.

Correspondence and requests for materials should be addressed to D.K. or Y.G.

Reprints and permissions information is available at www.nature.com/reprints.

Publisher's note Springer Nature remains neutral with regard to jurisdictional claims in published maps and institutional affiliations. 
(c) (i) Open Access This article is licensed under a Creative Commons Attribution 4.0 International cc) License, which permits use, sharing, adaptation, distribution and reproduction in any medium or format, as long as you give appropriate credit to the original author(s) and the source, provide a link to the Creative Commons licence, and indicate if changes were made. The images or other third party material in this article are included in the article's Creative Commons licence, unless indicated otherwise in a credit line to the material. If material is not included in the article's Creative Commons licence and your intended use is not permitted by statutory regulation or exceeds the permitted use, you will need to obtain permission directly from the copyright holder. To view a copy of this licence, visit http://creativecommons.org/licenses/by/4.0/.

(C) The Author(s) 2021 